\title{
A new diagnostic perspective - hyperglycemia in pregnancy - as of the year, 2014
}

\author{
Katarzyna Strawa-Zakoscielna ${ }^{1}$, Monika Lenart-Lipinska ${ }^{2}$, Aneta Szafraniec ${ }^{1}$, \\ Grzegorz Rudzki ${ }^{1}$, Beata Matyjaszek-MatuszeK ${ }^{1 \star}$
}

\begin{abstract}
${ }^{1}$ Department of Endocrinology, Medical University of Lublin, Jaczewskiego 8, Lublin, Poland
${ }^{2}$ Department of Laboratory Diagnostics, Medical University of Lublin, Chodzki 1, Lublin, Poland
\end{abstract}

\section{ARTICLE INFO}

Received 05 December 2014

Accepted 15 December 2014

Keywords:

Gestational Diabetes Mellitus,

GDM,

diabetes in pregnancy.

\begin{abstract}
Gestational Diabetes Mellitus (GDM) is a growing epidemiological problem, and it is currently the most common metabolic disorder in pregnancy, as it affects approximately $2-6 \%$ of all pregnant women. In 2014, the Polish Diabetic Association introduced significant changes in the diagnosis of hyperglycemia as first diagnosed in pregnancy, based on the recommendations of the IADPSG of 2010 and WHO of 2013. There are now two categories: diabetes in pregnancy, and GDM. These involve different degrees of severity of metabolic complications for the mother and the growing fetus. Establishing a new diagnostic criterion is significant because of the negative impact of hyperglycemia on the fetus (especially in the first trimester), the increased prevalence of malformations or the possibility of spontaneous abortions in early pregnancy.
\end{abstract}

\section{INTRODUCTION}

The year 2014 has been an important year for Diabetology in Poland, because of significant changes in the diagnostic criteria for hyperglycemia during pregnancy. Gestational Diabetes Mellitus (GDM) is a growing epidemiological problem, and as of now, it is the most common metabolic disorder in pregnancy. This disorder affects approximately $2-6 \%$ of all pregnant women. In 2014, the Polish Diabetic Association (PDA) introduced new criteria for the classification of hyperglycemia as first diagnosed in pregnancy. There are two categories, diabetes in pregnancy and GDM. Both of these involve different degrees of severity of metabolic complications for the mother and the growing fetus. The results of the multinational Hyperglycemia and Adverse Pregnancy Outcomes (HAPO) Study played an important role in introducing this new diagnostic criteria for GDM within Poland.

\section{HYPERGLYCEMIA IN PREGNANCY - DEFINITION}

Until 2013, any impaired carbohydrate metabolism that occurred or was diagnosed for the first time in the current

\footnotetext{
Corresponding author

e-mail: bmm@2com.pl

tel. +48 (81) 7244668

fax: + 48 (81) 7244669
}

gestation, irrespective of the treatment, was classified as being GDM. However, many studies have shown that, in most cases, GDM is a slowly developing form of type 2 diabetes that is at the stage of increasing insulin resistance $[3,16]$. The then definition of GDM stresses that the onset and prevalence of the symptoms are limited only to the period of pregnancy, as most often, it has been observed that they disappeared after the mother gives birth to her child [11]. Therefore, such definition included a wide range of disorders: overt diabetes, pre-diabetes, impaired fasting glucose (IFG) and impaired glucose tolerance (IGT). The clinical course of GDM has been associated with slow developing type 2 diabetes or already existing but not diagnosed diabetes, most often type 2 . Significantly more rarely, GDM presents itself as a developing latent autoimmune diabetes mellitus in adults (LADA) or a maturity onset diabetes of the young (MODY). In 2010, the International Association of Diabetes and Pregnancy Study Groups (IADPSG), on the basis of the results of the HAPO Study, issued new recommendations on screening and diagnosis of diabetes in pregnancy $[13,14]$. The HAPO Study, which examined 25,000 pregnant women, showed that the adverse outcomes for the mother, the fetus and the newborn are directly dependent on the glucose level of the mother between the 24 and 28 weeks of gestation [13]. In 2014, the PDA introduced a new classification of disorders of carbohydrate metabolism 
in gestation, making a clear distinction between GDM and diabetes in pregnancy $[1,7,20]$. Establishing a new diagnostic criterion is significant because of the negative impact of hyperglycemia on the fetus (especially in the first trimester), the increased prevalence of malformations or the possibility of spontaneous abortions in early pregnancy.

\section{GDM IN POLAND AND WORLDWIDE - EPIDEMIOLOGY}

The prevalence of GDM differs from to country to country, though it reflects general tendencies of the spread of type 2 diabetes around the world [12]. Ethnic background has been shown to be an independent risk factor for GDM; therefore, the prevalence of this disorder is proportional to the prevalence of type 2 diabetes in a given population or ethnic group [3]. The general incidence of this disorder ranges between $2-6 \%$, but it can reach even $10-20 \%$ in high risk populations. What is more, there is a growing tendency of developing the disorder among predisposed ethnic groups [9].

In the American population, $1.4-12.3 \%$ of all pregnant women suffer from this condition (depending on the state), and the ADA estimates that the average prevalence amounts to $7 \%$ of all pregnancies [8]. In the United Kingdom, GDM is still a rising health issue which now affects $7 \%$ of all pregnant women [10]. In the German population, we can observe more optimistic data, as the range of prevalence is from 0.3 to $1.4 \%$ [17]. In Poland, however, there have been few epidemiological studies, and according to Wójcikowski et al., GDM prevalence in different parts of the country is from 2.0 to $3.8 \%$ [19].

\section{GDM PATHOGENESIS}

The pathogenesis of GDM is a complicated and still unclear process that involves a complex interaction of abnormalities with a dominating defect within the pancreatic $\beta$-cell and an insulin resistance. This, progresses until the third trimester of gestation. In patients predisposed to the development of GDM, we can observe a defect in insulin secretion, which, accompanied with insulin resistance, leads to the development of carbohydrate metabolism disorders of different severity $[11,4]$. GDM is characterized by the chronic insulin resistance of peripheral tissues due to multifactorial etiology. It comes about by way of genetic defects, hormonal factors secreted by the placenta, and (currently, intensively clinically studied) insulin resistance markers that are evident within the adipose tissue (among these, proinflammatory cytokines and adipokines).

A further factor considered in the pathogenesis of GDM is impaired insulin secretion, both in terms of quantity and quality. It is thought that $\beta$-cell dysfunction in GDM is mainly characterized by deficient insulin secretion where even the compensatory increase in insulin necessary to overcome severe insulin resistance in late pregnancy, may be insufficient to restore normal glucose [15].

Molecular insulin resistance etiology in normal pregnancy is connected with a post-receptor defect, as the affinity of insulin receptor is not altered. It is believed that such defect is associated with impaired autophosphorylation within insulin receptor beta-subunits, decreased expression of the adaptor protein of the insulin receptor substrate-1 (IRS-1) and increased concentration of the prototypic $\mathrm{p} 85$ regulatory subunit of PI 3-kinase (PI3K). The consequence of such disorders is decreased PI3K activity i.e. the insulin pathway leading to the translocation of glucose transporters [2].

Insulin resistance in pregnancy is directly associated with the secretion of hyperglycemic hormones produced by the placenta. First, there is progesterone, cortisol, and then placental lactogen, as well as prolactin, and, finally, the growth hormone. These hormones antagonize insulin action, and lead to the relative insulin resistance which is characteristic in the course of normal gestation. What is more, insulin resistance, which quickly subsides after delivery, may support the important role played by the hormonal function of the placenta. An additional element increasing physiological insulin resistance during pregnancy is the gradual obesity associated with the redistribution of adipose tissue, which, altogether, leads to the development of a pro-diabetic metabolic environment in pregnant women [18].

Another factor intensifying insulin resistance in the course of a normal gestation is the endocrine activity of adipose tissue, especially that which is visceral. It is believed that increased secretion of proinflammatory mediators (such as the tumor necrosis factor or acute-phase proteins) and also the impaired secretion of adipokines (especially adiponectin) through the adipose tissue and/or the placenta, are important mechanisms which participate in the development of physiological insulin resistance in the course of gestation [5].

\section{NEW DIAGNOSTIC CRITERIA FOR GDM}

Because of the different medical problems that come about, GDM should be distinguished from pre-gestational diabetes mellitus (PGDM). PGDM is diabetes diagnosed before pregnancy. Most frequently it is a type 1 diabetes, LADA or MODY, and it constitutes approximately $10 \%$ of all cases of diabetes in pregnancy. Type 2 diabetes occurs more rarely, and is diagnosed in older women exhibiting features of the metabolic syndrome.

Given the fact that the course of GDM is asymptomatic, screening tests in all pregnant women, especially those with risk factors for the development of diabetes, are recommended. Theae tests will allow for quick diagnosis and the prompt treatment that aims at preventing adverse outcomes of GDM in the mother and the child.

Until 2013, the Polish diagnostic algorithm of GDM was based on the recommendations of the WHO [6]. It involved two stages, and, until 2011, it was based on screening tests conducted between 24 and 28 weeks of gestation and the 2-hour $75 \mathrm{~g}$ OGTT, with glucose ranges typical for the general population (Table 1). The results of the HAPO Study published in 2008, showed that the increase in glucose of pregnant women, enhances the risk of macrosomy, hyperinsulinemia and hyperglycemia in the newborn, cesarean section or perinatal trauma. What is more, it has been revealed that the main clinical endpoints occurred at lower glucose levels (especially that of fasting), than it was 
thought before. These observations suggested the necessity of lowering the diagnostic thresholds for GDM.

In response to the results of the HAPO Study, in 2010, the International Association of Diabetes and Pregnancy Study Groups (IADPSG) published new recommendations for the screening of diabetes, as well as for its diagnostic tests. These were implemented by most diabetic associations, including the ADA [1,14]. In 2014, the PDA introduced significant changes in the way in which a diagnosis of GDM is made, based on the recommendations of the IADPSG of 2010 and WHO of 2013. The main recommendations include diagnosis of pre-gestational diabetes mellitus in women with high risk, at the first prenatal visit, and universal screening tests between 24 and 28 weeks of gestation, with the use of the three point OGTT. Any abnormality: fasting or at 60 or 120 minutes, constitutes a basis for diagnosing GDM. In accordance with this diagnosis, the subsequent decision on a further diagnostic plan should be then taken at the first prenatal visit after conducting a fasting plasma glucose test. The new diagnostic criteria of the PDA are shown in Table 1. An important diagnostic step is ascertaining the potential GDM risk factors so as to isolate the group of pregnant women with high risk of developing this disorder (Table 2). Following this, the patients from the risk group should undergo a $75 \mathrm{~g}$ OGTT after their first prenatal visit or even during the pre-gestational period.

Table 1. Comparison of GDM diagnostic criteria according to the recommendations of the PDA of 2013 and 2014 [6,20]

\begin{tabular}{|c|c|c|c|c|}
\hline \multirow{3}{*}{ Time } & \multicolumn{2}{|c|}{2013} & \multicolumn{2}{|c|}{2014} \\
\hline & \multicolumn{4}{|c|}{ Plasma glucose } \\
\hline & {$[\mathrm{mg} / \mathrm{dl}]$} & {$[\mathrm{mmol} / \mathrm{l}]$} & {$[\mathrm{mg} / \mathrm{dl}]$} & {$[\mathrm{mmol} / \mathrm{l}]$} \\
\hline Fasting & $\geq 100$ & $\geq 5.6$ & $92-125$ & $5.1-6.9$ \\
\hline 60' OGTT (75g) & $\geq 180$ & $\geq 10.0$ & $\geq 180$ & $\geq 10.0$ \\
\hline 120' OGTT $(75 \mathrm{~g})$ & $\geq 140$ & $\geq 7.8$ & $\geq 153-199$ & $\geq 8.5-11.0$ \\
\hline
\end{tabular}

Table 2. GDM risk factors [6,20]

\begin{tabular}{|c|c|}
\hline \multicolumn{2}{|c|}{ History of type 2 diabetes } \\
\hline 1. & $\begin{array}{c}\left.\text { Overweight and obesity (BMI }>27 \mathrm{~kg} / \mathrm{m}^{2}\right) \\
\text { and hypertension before gestation }\end{array}$ \\
\hline 2. & Multiparity \\
\hline 3. & Gestation after 35 years of age \\
\hline 4. & History of GDM \\
\hline 5. & Giving birth to a child with weight $>4000 \mathrm{~g}$ \\
\hline 6. & Giving birth to a child with a developmental defect \\
\hline 7. & GDM diagnosed in the patient's mother \\
\hline Additional risk factors \\
\hline 1. & Small height (<151cm), low $(<2000 \mathrm{~g})$ or high $(>4000 \mathrm{~g})$ \\
\hline 2. & Hirth weight of the pregnant woight gain in pregnancy \\
\hline 3. & High intake of saturated fatty acids \\
\hline 4. & History of Polycystic Ovary Syndrome \\
\hline 5. & \\
\hline
\end{tabular}

Nonetheless, we should stress that the new classification of hyperglycemia diagnosed for the first time during pregnancy, distinguishes between GDM and diabetes in pregnancy. This disorder is diagnosed in pregnancy when the patient complies with the general diagnostic criteria for diabetes (Table 3). Diabetes in pregnancy is believed to be more dangerous for the mother and the newborn, in comparison to GDM; therefore, it is vital to make a distinction between these disorders.

Table 3. Criteria for diabetes in pregnancy according to the recommendations of the IADPSG and WHO of 2013 [20]

\begin{tabular}{|l|c|c|}
\hline \multirow{2}{*}{\multicolumn{1}{|c|}{ Time }} & \multicolumn{2}{c|}{ Plasma glucose } \\
\cline { 2 - 3 } & {$[\mathrm{mg} / \mathrm{dl}]$} & {$[\mathrm{mmol} / \mathrm{l}]$} \\
\hline Fasting & $\geq 126 \mathrm{mg} / \mathrm{dl}$ & $7.0 \mathrm{mmol} / \mathrm{l}$ \\
\hline $120^{\prime}$ OGTT $(75 \mathrm{~g})$ & $\geq 200 \mathrm{mg} / \mathrm{dl}$ & $\geq 11.1 \mathrm{mmol} / \mathrm{l}$ \\
\hline incidental glucose & $\geq 200 \mathrm{mg} / \mathrm{dl}$ & $\geq 11.1 \mathrm{mmol} / \mathrm{l}$ \\
\hline
\end{tabular}

\section{CRITERIA FOR METABOLIC CONTROL IN PREGNANCY}

Irrespective of the causes of hyperglycemia in pregnancy, it is recommended that fasting glucose should be within a range of $60-90 \mathrm{mg} / \mathrm{dl}$, while the postprandial should not exceed $120 \mathrm{mg} / \mathrm{dl}$ (Table 4). HbA1c in pregnancy is also believed to play an important role in metabolic control in GDM, and it should not be over 6.0\%. Pregnant women should have its level assessed every six weeks; however, the PDA is more inclined to stress the significance of this parameter in PGDM.

Table 4. Metabolic control criteria in pregnancy (self-monitoring) according to the recommendations of the PDA of 2014 [20]

\begin{tabular}{|l|c|c|}
\hline \multirow{2}{*}{\multicolumn{1}{|c|}{ Time }} & \multicolumn{2}{c|}{ Plasma glucose } \\
\cline { 2 - 3 } & {$[\mathrm{mg} / \mathrm{dl}]$} & {$[\mathrm{mmol} / \mathrm{l}]$} \\
\hline Fasting and preprandial & $60-90$ & $3.3-5.0$ \\
\hline $\begin{array}{l}\text { Postprandial maximum glucose } \\
\text { level after 1h }\end{array}$ & $<120$ & $<6.7$ \\
\hline Between 2 and 4 a.m. & $>60$ & $>3.3$ \\
\hline
\end{tabular}

\section{SUMMARY}

GDM is the most common metabolic complication during pregnancy. A thorough understanding of the etiopathogenesis of GDM and an early diagnosis of metabolic disorders in pregnancy helps minimize the adverse outcomes of chronic hyperglycemia. A proper diagnostic procedure, based on the new criteria that is in accordance with the IADPSG of 2010 and WHO of 2013, together with appropriate treatment, may decrease the risk of complications - both for the mother and her growing fetus. At the same time, we should remember that GDM is a future risk factor for type 2 diabetes for the mother. Typically six to 12 weeks following the delivery, it is recommended that any patients with a history of GDM should undergo re-diagnosis of carbohydrate metabolism, using the $75 \mathrm{~g}$ OGTT. Moreover, the follow-up should include a fasting glucose test conducted once a year.

\section{DECLARATION OF INTEREST}

The authors declare that there is no conflict of interest that could be perceived as prejudicing the impartiality of this review. 


\section{REFERENCES}

1. American Diabetes Association: Diagnosis and classification of diabetes mellitus. Diabetes Care, 2014 Jan; 37 Suppl 1: 81-90.

2. Barbour L.A. et al.: Cellular mechanisms for insulin resistance in normal pregnancy and gestational diabetes. Diabetes Care, 30, 112-19, 2007.

3. Ben-Haroush A., Yogev Y., Hod M.: Epidemiology of gestational diabetes mellitus and its association with Type 2 diabetes. Diabet Med, 21[2], 103-13, 2004.

4. Briana D.D., Malamitsi-Puchner A.: Reviews: adipocytokines in normal and complicated pregnancies. Reprod Sci, 16 (10), 921-37, 2009.

5. Buchanan T.A. et al.: What is gestational diabetes? Diabetes Care, 30, 105-11, 2007.

6. Cypryk K., Wender-Ożegowska E.: Ciąża powikłana cukrzycą. W: Moczulski D. (red.) Diabetologia. Medical Tribune Polska. Warszawa 2010; 108-118. ISBN 978-83-60135-85-3.

7. Diagnostic criteria and classification of hyperglycaemia first detected in pregnancy: a World Health Organization Guideline. Diabetes Res Clin Pract. 2014.

8. Ferrara A. et al.: Prevalence of gestational diabetes mellitus detected by the national diabetes data group or the Carpenter and Coustan plasma glucose thresholds. Diabetes Care, 25 (9), 1625-30, 2002.

9. Galtier F.: Definition, epidemiology, risk factors. Diabetes Metab, 36, 628-51, 2010.

10. Hayes C.: Long-term prognostic factors in the diagnosis of gestational diabetes. Br J Nurs, 18(9), 523-34, 2009.
11. Jovanovic L., Pettitt D.J.: Gestational diabetes mellitus. JAMA, 286(20), 2516-18, 2001

12. Karagiannis T. et al.: Gestational diabetes mellitus: why screen and how to diagnose. Hippokratia, 14[3], 151-4, 2010.

13. Metzger B.E. et al.: Hyperglycemia and adverse pregnancy outcomes. HAPO Study Cooperative Research Group, N Engl J Med, 358 (19), 1991-2002, 2008.

14. Metzger B.E. et al.: International association of diabetes and pregnancy study groups recommendations on the diagnosis and classification of hyperglycemia in pregnancy. Diabetes Care, 33[3], 676-82, 2010.

15. Retnakaran R. et al.: Adiponectin and beta cell dysfunction in gestational diabetes: pathophysiological implications. Diabetologia, 48 (5), 993-1001, 2005.

16. Retnakaran R. et al.: Reduced adiponectin concentration in women with gestational diabetes: a potential factor in progression to type 2 diabetes. Diabetes Care, 27, 799-800, 2004.

17. Schäfer-Graf U.M. et al.: Diagnostik und Therapie des Gestationsdiabetes (GDM) [online]. W: Deutsche Gesellschaft für Gynäkologie und Geburtshilfe e.V. Dostępny w World Wide Web: http://www.dggg.de/fileadmin/public_docs/Leitlinien/3-3-3gestationsdiabetes-2010.pdf.

18. Valsamakis G. et al.: The effects of adipose tissue and adipocytokines in human pregnancy. Ann N Y Acad Sci, 1205, 76-81, 2010.

19. Wójcikowski C. et al.: The prevalence of gestational diabetes mellitus in the Polish population. Ginekol Pol, 73 (10), 811-16, 2002.

20. Zalecenia kliniczne dotyczące postępowania u chorych na cukrzycę 2014. Stanowisko Polskiego Towarzystwa Diabetologicznego. Diabetol Klin, 3, supl A, 46-9, 2014. 